\title{
Current clinical nutrition practices in critically ill patients in Latin America: a multinational observational study
}

Karin Papapietro Vallejo ${ }^{1}$, Carolina Méndez Martínez ${ }^{2}$, Alfredo A. Matos Adames ${ }^{3}$, Vanessa Fuchs-Tarlovsky ${ }^{4}$, Guillermo Carlos Contreras Nogales ${ }^{5}$, Roger Enrique Riofrio Paz ${ }^{6}$, Mario Ignacio Perman? Maria Isabel Toulson Davisson Correia ${ }^{8^{*}}$ (D) and Dan Linetzky Waitzberg ${ }^{9}$

\begin{abstract}
Background: Malnutrition in critically ill adults in the intensive care unit (ICU) is associated with a significantly elevated risk of mortality. Adequate nutrition therapy is crucial to optimise outcomes. Currently, there is a paucity of such data in Latin America. Our aims were to characterise current clinical nutrition practices in the ICU setting in Latin America and evaluate whether current practices meet caloric and protein requirements in critically ill patients receiving nutrition therapy.

Methods: We conducted a cross-sectional, retrospective, observational study in eight Latin American countries (Argentina, Brazil, Chile, Colombia, Ecuador, Mexico, Panama, and Peru). Eligible patients were critically ill adults hospitalised in the ICU and receiving enteral nutrition (EN) and/or parenteral nutrition (PN) on the Screening Day and the previous day (day -1). Caloric and protein balance on day -1 , nutritional status, and prescribed nutrition therapy were recorded. Multivariable logistic regression analysis was performed to identify independent predictors of reaching daily caloric and protein targets.

Results: The analysis included 1053 patients from 116 hospitals. Evaluation of nutritional status showed that $74.1 \%$ of patients had suspected/moderate or severe malnutrition according to the Subjective Global Assessment. Prescribed nutrition therapy included EN alone (79.9\%), PN alone (9.4\%), and EN + PN (10.7\%). Caloric intake met $>90 \%$ of the daily target in $59.7 \%$ of patients on day -1 ; a caloric deficit was present in $40.3 \%$, with a mean $( \pm$ SD) daily caloric deficit of $-688.8 \pm 455.2 \mathrm{kcal}$. Multivariable logistic regression analysis showed that combined administration of EN + PN was associated with a statistically significant increase in the probability of meeting $>90 \%$ of daily caloric and protein targets compared with EN alone (odds ratio, 1.56; 95\% confidence interval, 1.02-2.39; $p=0.038)$.

Conclusions: In the ICU setting in Latin America, malnutrition was highly prevalent and caloric intake failed to meet targeted energy delivery in $40 \%$ of critically ill adults receiving nutrition therapy. Supplemental administration of PN was associated with improved energy and protein delivery; however, PN use was low. Collectively, these findings suggest an opportunity for more effective utilisation of supplemental PN in critically ill adults who fail to receive adequate nutrition from $\mathrm{EN}$ alone.
\end{abstract}

Keywords: Disease-related malnutrition, Caloric balance, Intensive care, Enteral nutrition, Parenteral nutrition

\footnotetext{
*Correspondence: isabel_correia@uol.com.br

${ }^{8}$ Universidade Federal de Minas Gerais Medical School, Av. Carandaí 246 Apt.

902, Belo Horizonte 30130-060, Brazil

Full list of author information is available at the end of the article
} 


\section{Background}

Disease-related malnutrition in hospitalised patients is a highly prevalent but frequently under-recognised condition and a major public health problem [1]. Poor nutritional status is associated with significant clinical and economic consequences, including increased risk of infectious and non-infectious complications, prolonged duration of stay in the hospital and intensive care unit (ICU), more frequent readmission, and increased mortality [2-10]. This is especially true in critically ill patients, as the catabolic state induced by the systemic inflammatory response to critical illness or trauma markedly increases metabolic demands, thereby accelerating the development of malnutrition and further increasing the risk of infectious complications, multi-organ dysfunction, and mortality $[11,12]$.

Providing adequate nutrition is an integral part of the treatment of critically ill patients $[11,12]$. Evidence suggests it can attenuate the metabolic response to stress, prevent cellular injury, and promote a favourable immune response [11]. Studies in medical and surgical intensive care populations have demonstrated that adequate nutrition therapy is associated with a decrease in infectious morbidity [13, 14], length of hospital stay [13-15], and mortality $[15,16]$. Current clinical practice guidelines for the nutritional management of critically ill patients differ with respect to the use and timing of initiating parenteral nutrition (PN) as well as the optimal daily caloric and protein intake. The European and North American guidelines advocate early enteral nutrition (EN) in critically ill patients who are unable to maintain oral intake $[11,12,17]$. The European Society for Clinical Nutrition and Metabolism (ESPEN) guidelines further recommend early initiation of $\mathrm{PN}$ in all patients for whom EN is contraindicated or not tolerated [12], while the American Society for Parenteral and Enteral Nutrition (A.S.P.E.N.) guidelines recommend early use of $\mathrm{PN}$ in patients with evidence of malnutrition on admission when EN is not feasible [11, 17]. Both the ESPEN and A.S.P.E.N. guidelines recommend the use of supplemental $\mathrm{PN}$ in patients who are unable to meet the targeted energy and protein intake via the enteral route. The ESPEN guidelines recommend initiating supplemental PN in patients who fail to reach the targeted intake by day 3 , while the A.S.P.E.N. guidelines indicate supplemental PN should be considered after 7-10 days in patients who are unable to meet $>60 \%$ of energy and protein requirements $[11,12]$. Recently published clinical practice guidelines from the European Society of Intensive Care Medicine (ESICM) advocate the use of early enteral nutrition in the majority of critically ill patients and identify specific clinical circumstances when EN should be delayed; however, the nutritional management of patients for whom EN is insufficient or contraindicated is not specifically addressed [18].
A recent prospective observational study evaluating the nutritional status of 185 critically ill patients admitted to the ICU in a Brazilian hospital reported an overall prevalence of malnutrition of $54.5 \%$. The prevalence was even higher $(70.3 \%)$ among patients who were hospitalised more than 48 hours before admission to the ICU [19]. Moreover, multivariate logistic regression analysis showed a twofold increase in the risk of readmission to the ICU and an eightfold increase in the risk of death among patients who were malnourished compared with well-nourished patients. These findings underscore the need for the development of evidence-based clinical nutrition practices aimed at the proactive identification of nutritional needs and the optimal nutritional management of critically ill patients. To gain insights that will inform subsequent recommendations, we conducted a multinational observational study ("Screening Day Latin America") to characterise current clinical nutrition practices in the intensive care setting in Latin America and evaluate the degree to which current practices meet the daily caloric requirements in critically ill patients receiving $\mathrm{EN}$ and/or PN.

\section{Methods \\ Study design}

The Screening Day study was a multinational, crosssectional, retrospective observational study evaluating clinical nutrition practices in critically ill adults in the intensive care setting in eight Latin American countries (Argentina, Brazil, Chile, Colombia, Ecuador, Mexico, Panama, and Peru). The observation period was defined as the period from the Screening Day (day 0) up to a maximum of 5 days in the ICU before the Screening Day (day -5) (Fig. 1). Demographic and clinical characteristics, nutritional status, nutrition-related risk, type and volume of nutrition therapy, and daily caloric and protein balance during the observation period were assessed by investigators on the Screening Day.

The study protocol was approved by the local ethics committee or institutional review board at each participating institution. Where required by local regulations or ethics committee policy, written informed consent was obtained from each patient or family member before enrollment. The study was funded and organised by Fresenius Kabi Deutschland GmbH, Bad Homberg, Germany. Statistical analysis was performed by IMS Health S.A., Madrid, Spain.

\section{Study population}

Eligible patients were critically ill adults (age $\geq 18$ years) who were hospitalised in the ICU and received EN and/ or PN on both the Screening Day (day 0) and the previous day (day -1$)$. For the purpose of eligibility, a critically ill patient was defined as a patient with at least 


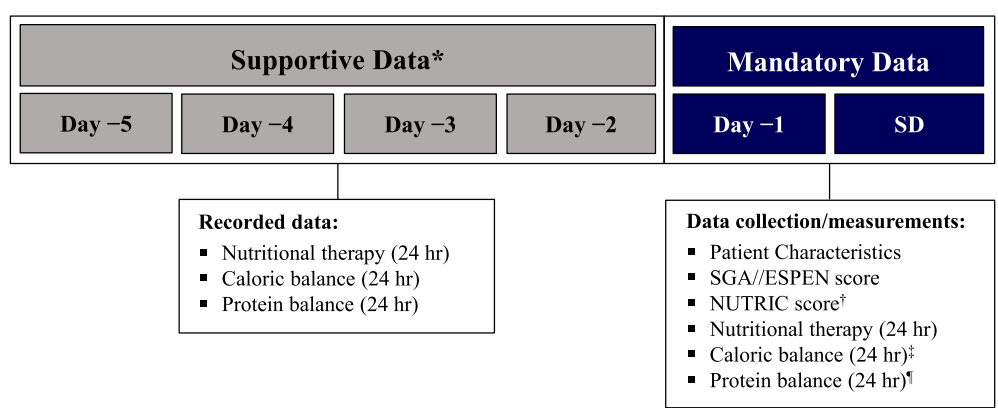

Fig. 1 Study design. *Available data from patient records collected for each day of stay in the ICU during the period from day -5 to day $-2 .{ }^{\dagger}$ NUTRIC score calculated based on data in the patients' medical file collected at the time of ICU admission. ${ }^{\ddagger}$ Calculated as the difference between the daily caloric target and the daily calories provided by enteral and/or parenteral nutrition plus other sources of caloric intake. "Calculated as the difference between the clinician-derived daily protein target and the daily protein intake. Abbreviations: ESPEN European Society for Clinical Nutrition and Metabolism, NUTRIC nutrition risk in the critically ill, SD Screening Day, SGA Subjective Global Assessment

one organ failure; critically ill burn patients and patients admitted to the ICU for surveillance only were excluded from enrollment.

\section{Measurements and outcomes}

The primary study outcome was the daily caloric balance on day -1 . The daily caloric balance was calculated as the difference between the daily caloric target and the daily calories provided by EN and/or PN. The daily caloric target was derived by the clinician using one of four methods: calculation using a predictive equation (HarrisBenedict equation), estimation (total daily caloric requirement as estimated by the physician), standard formula (standardised daily target per kilogram actual body weight), or indirect calorimetry. Additionally, a sensitivity analysis of the primary outcome was performed using a standard formula to calculate the daily caloric target for each patient $(20 \mathrm{kcal} / \mathrm{kg}$ actual body weight on the Screening Day for those on the first 6 days in the ICU and $25 \mathrm{kcal} / \mathrm{kg}$ actual body weight on the Screening Day for those in the ICU after day 6). For obese patients $\left(B M I \geq 30 \mathrm{~kg} / \mathrm{m}^{2}\right)$, the caloric target was calculated based on ideal body weight, as determined by height using the formula by Hamwi [20].

Secondary outcomes included the cumulative caloric balance during the observation period (days -5 to -1 ), daily protein balance on day -1 , cumulative protein balance (days -5 to -1 ), patient nutritional status and nutrition-related risk (day 0), and use of EN and PN during the 5-day observation period. Daily protein balance was calculated as the difference between the clinicianderived daily protein target and the daily protein intake. In contrast to the caloric balance, sensitivity analysis based on a standard equation was not performed, as the defined protein target must be adapted based on certain clinical conditions (e.g. renal and hepatic insufficiency). Cumulative caloric balance and cumulative protein balance were defined as the sum of the mean daily balance for all days from day -5 , calculated for each day from day -5 to day -1 (e.g. the cumulative balance on day -3 was calculated as the sum of the mean daily balance on days $-5,-4$, and -3 ). Patient nutritional status was determined according to the Subjective Global Assessment (SGA) questionnaire and the ESPEN malnutrition score; nutrition-related risk was determined based on the Nutrition Risk in the Critically Ill (NUTRIC) score (Additional file 1: Appendices A-C) [21-25]. For the latter, the score was calculated based on data in the patients' medical file collected at the time of ICU admission. Physical exams, patient interviews, and chart reviews were performed by the investigators on the Screening Day. If a patient was unable to participate in the interview, the patient's relative was interviewed to obtain the requisite information.

Hospital characteristics, including the number of beds in the hospital and ICU, the type and volume of nutrition therapies prescribed, the availability of a nutrition therapy team, and institutional nutrition management policies and practices were recorded by the investigator at each participating institution using an electronic case report form.

\section{Statistical methods}

The analysis population was defined according to the per protocol principle and included all patients with complete data for the protocol-defined mandatory variables and without a protocol violation (e.g. failure to meet all eligibility criteria). Data are summarised descriptively using number and percentage for categorical variables and mean \pm standard deviation (SD) as well as median for continuous variables. The primary outcome is presented both as a continuous variable using the mean (SD) difference between the daily caloric target and the daily caloric intake and as a categorical variable using the number and percentage of patients in each of the following categories: meets $>90 \%$ of daily target and 
caloric deficit ( $\leq 90 \%$ of daily target). The primary outcome was also analysed in subpopulations defined according to the following parameters: sex, nutritional status, type of nutritional therapy, reason for admission to the ICU, duration of stay in the ICU before the Screening Day, Acute Physiology and Chronic Health Evaluation (APACHE) II score, and Sequential Organ Failure Assessment (SOFA) score.

Univariable and multivariable logistic regression models were used to explore the relationship between the daily caloric and protein balance on day -1 and selected hospital and patient characteristics. All variables with a $p$ value $\leq 0.20$ in the unadjusted univariable analysis were included in the multivariable analysis. Final model specification was based on a backward step-wise elimination of variables with a $p$ value $>0.05$. Results are reported as the adjusted odds ratio (OR) and $95 \%$ confidence interval (95\% CI) for each variable. All analyses were performed using SAS Enterprise Guide 6.1 running SAS 9.4 (SAS Institute Inc., Cary, NC, USA).

Sample size calculations were based on an estimated prevalence of disease-related malnutrition of 50\%, derived from the results of prior multinational epidemiological studies in Latin America $[9,26]$. It was determined that a sample size of 2000 patients would provide a confidence interval with a precision of $\pm 2.2 \%$.

\section{Results}

A total of 1053 patients in 116 hospitals in eight Latin American countries met the criteria for eligibility and consented to participate in the study (Table 1). The majority of participating institutions were academic/university hospitals (94 [81.0\%]) providing tertiary care services (93 [80.2\%]). A total of 46 (39.7\%) hospitals reported having a nutrition therapy team in the ICU; of these, 36 (78.3\%) were academic/university hospitals (hospital characteristics are summarised in Additional file 1: Appendix D).

Patient characteristics are summarised in Table 2. The mean $( \pm \mathrm{SD})$ age was $58.6 \pm 19.0$ years and the mean duration of ICU stay on the Screening Day was $27.6 \pm 62.2$ days. The most common primary reasons for admission to the

Table 1 Study enrollment summary ${ }^{a}$

\begin{tabular}{lll}
\hline Country & Hospitals, $\mathrm{n}$ & Patients, $\mathrm{n}$ \\
\hline Argentina & 16 & 110 \\
Brazil & 13 & 133 \\
Chile & 20 & 211 \\
Colombia & 22 & 229 \\
Ecuador & 14 & 103 \\
Mexico/Panama & 16 & 129 \\
Peru & 15 & 138 \\
Total & 116 & 1053 \\
\hline
\end{tabular}

${ }^{\mathrm{a}}$ See Additional file 1: Appendix $\mathrm{F}$ for a complete list of study sites
ICU were respiratory illness (315 [30.0\%]), neurologic illness (234 [22.3\%]), sepsis (210 [20.0\%]), and trauma (102 [9.7\%]). Approximately half of the patients (47.3\%) were classified as surgical patients. Invasive respiratory support was required in $799(75.9 \%)$ patients. A total of 841 (79.9\%) patients received EN only, $113(10.7 \%)$ received both EN and $\mathrm{PN}$, and 99 (9.4\%) received PN only.

\section{Daily caloric balance}

Clinician-derived daily energy requirements were established for $800(76 \%)$ patients using one of the following methods: estimation (44.1\%), predictive equation (31.3\%), standardised formula (23.4\%), or indirect calorimetry (1.3\%). In 253 (24\%) patients, no clinician-derived energy target was given. In these patients, a daily caloric target of $20 \mathrm{kcal} / \mathrm{kg}$ actual body weight $(25 \mathrm{kcal} / \mathrm{kg}$ for patients with $\geq 6$ days in the ICU) was assigned.

The mean daily caloric balance on day -1 is presented in Table 3. Categorical analysis of daily caloric balance on day -1 showed that caloric intake met $>90 \%$ of the daily target in 628 (59.7\%) patients and resulted in a caloric deficit in 424 (40.3\%) patients (Fig. 2). Among those who did not reach the caloric target, the mean caloric deficit on day -1 was $-688.8 \pm 455.2 \mathrm{kcal}(-10.8 \pm$ $7.0 \mathrm{kcal} / \mathrm{kg}$ ). Sensitivity analysis using a standardised daily caloric target of $20 \mathrm{kcal} / \mathrm{kg}$ actual body weight ( $25 \mathrm{kcal} / \mathrm{kg}$ for patients with $\geq 6$ days in the ICU) yielded similar results; caloric intake met $>90 \%$ of the standardised daily caloric target in 607 (60.3\%) patients and resulted in a caloric deficit in 399 (39.7\%) patients. The mean caloric deficit among patients who failed to meet the standardised daily caloric target on day -1 was $640.3 \pm 373.2 \mathrm{kcal}(-9.5 \pm 5.1 \mathrm{kcal} / \mathrm{kg})$.

Assessment of daily caloric balance according to the prescribed route of nutrition support showed that the proportion of patients with a caloric deficit was higher among those who received EN alone (42.4\%) compared with either PN alone (36.4\%) or a combination of EN and PN (28.3\%) (Fig. 3).

Subgroup analysis according to nutritional status showed a lower incidence of caloric deficit on day -1 in patients who were classified as malnourished compared with those who were classified as well-nourished. Caloric deficits were observed in $29.5 \%$ and $43.1 \%$ of patients classified as malnourished and well-nourished, respectively, according to the ESPEN malnutrition score. Similarly, $36.7 \%$ of patients with suspected or moderate malnutrition according to the SGA had a caloric deficit on day -1 , compared with $41.6 \%$ of patients with severe malnutrition and $47.3 \%$ of those who were well nourished. Assessment of daily caloric balance on day -1 according to the NUTRIC score, which measures the risk of death if not adequately fed, showed no meaningful differences between patients with a score indicating a 
Table 2 Patient characteristics

\begin{tabular}{|c|c|c|c|c|}
\hline Characteristic & Total $(N=1053)$ & \multicolumn{3}{|c|}{ Comorbid conditions, $\mathrm{n}(\%)^{c}$} \\
\hline \multicolumn{2}{|l|}{ Age, years } & \multicolumn{2}{|l|}{0} & $137(14.2)$ \\
\hline Mean (SD) & $58.6(19.0)$ & \multicolumn{2}{|l|}{$1-5$} & $795(82.2)$ \\
\hline Median (range) & $61.0(18.0-99.0)$ & \multicolumn{2}{|l|}{$\geq 5$} & $35(3.6)$ \\
\hline \multicolumn{2}{|l|}{ Sex, n (\%) } & \multicolumn{3}{|c|}{ APACHE II score, n (\%) } \\
\hline Male & $602(57.2)$ & \multicolumn{2}{|l|}{$<15$} & $389(36.9)$ \\
\hline Female & $451(42.8)$ & \multicolumn{2}{|l|}{15 to $<20$} & $266(25.3)$ \\
\hline Height, cm & & \multicolumn{2}{|l|}{20 to $<28$} & $282(26.8)$ \\
\hline Mean (SD) & $163.3(9.6)$ & \multicolumn{2}{|l|}{$\geq 28$} & $116(11.0)$ \\
\hline Median (range) & 170.0 (135.0-196.0) & \multicolumn{3}{|c|}{ SOFA score, n (\%) } \\
\hline \multicolumn{2}{|l|}{ Mean weight, kg (SD) } & \multicolumn{2}{|l|}{$<6$} & $482(45.8)$ \\
\hline Screening Day & & \multicolumn{2}{|l|}{6 to $<10$} & $369(35.0)$ \\
\hline Mean (SD) & $68.8(17.6)$ & \multicolumn{2}{|l|}{$\geq 10$} & $202(19.2)$ \\
\hline Median (range) & $66.0(30.0-195.0)$ & \multirow{2}{*}{\multicolumn{2}{|c|}{$\begin{array}{l}\text { Requirement for invasive respiratory } \\
\text { support, } \mathrm{n}(\%)\end{array}$}} & 799 (75.9) \\
\hline Admission $^{a}$ & & & & \\
\hline Mean (SD) & $71.2(18.8)$ & \multirow{2}{*}{\multicolumn{3}{|c|}{$\begin{array}{l}\text { Abbreviations: } A P A C H E \text { Acute Physiology and Chronic Health Evaluation, } B M I \text { body } \\
\text { mass index, ICU intensive care unit, SD standard deviation, SOFA Sequential } \\
\text { Organ Failure Assessment }\end{array}$}} \\
\hline Median (range) & $70.0(30.0-240.0)$ & & & \\
\hline Mean BMI, kg/m² (SD) & $25.8(6.1)$ & \multicolumn{3}{|l|}{$\begin{array}{l}{ }^{\mathrm{a}} \mathrm{N}=896 \\
{ }^{\mathrm{b}} \mathrm{N}=1050\end{array}$} \\
\hline Age $<70$ years & $25.6(6.4)$ & \multicolumn{3}{|l|}{${ }^{\mathrm{c}} \mathrm{N}=967$} \\
\hline Age $\geq 70$ years & $26.0(5.6)$ & & & \\
\hline \multicolumn{5}{|l|}{ BMI, n (\%) } \\
\hline$<18.5 \mathrm{~kg} / \mathrm{m}^{2}$ & $69(6.6)$ & & & \\
\hline 18.5 to $<20 \mathrm{~kg} / \mathrm{m}^{2}$ & $57(5.4)$ & \multicolumn{3}{|c|}{ Table 3 Caloric balance on day $-1^{a}$} \\
\hline 20 to $<22 \mathrm{~kg} / \mathrm{m}^{2}$ & $131(12.4)$ & \multicolumn{3}{|c|}{ Per protocol population $(N=1053)$} \\
\hline 22 to $<30 \mathrm{~kg} / \mathrm{m}^{2}$ & $609(57.8)$ & \multirow{2}{*}{ 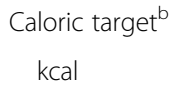 } & Mean & Median \\
\hline$\geq 30 \mathrm{~kg} / \mathrm{m}^{2}$ & $187(17.8)$ & & $1609.1(447.4)$ & $1611.0(1320.5 ; 1900.0)$ \\
\hline \multicolumn{2}{|l|}{ Type of nutrition, n (\%) } & $\mathrm{kcal} / \mathrm{kg}$ & $26.0(7.3)$ & $25.0(21.5 ; 30.0)$ \\
\hline Enteral nutrition only & $841(79.9)$ & Caloric intake & Mean & Median \\
\hline Parenteral nutrition only & $99(9.4)$ & kcal & $1463.2(683.1)$ & $1465.5(1000.0 ; 1800.0)$ \\
\hline Both parenteral and enteral nutrition & $113(10.7)$ & $\mathrm{kcal} / \mathrm{kg}$ & $24.0(11.8)$ & $23.9(16.0 ; 30.1)$ \\
\hline Primary reason for ICU admission, $\mathrm{n}(\%)^{\mathrm{b}}$ & & Caloric balance & Mean & Median \\
\hline Respiratory & $315(30.0)$ & kcal & $-146.1(653.0)$ & $-19.0(-460.0 ; 71.5)$ \\
\hline Neurologic & $234(22.3)$ & $\mathrm{kcal} / \mathrm{kg}$ & $-2.0(10.6)$ & $-0.2(-7.1 ; 1.2)$ \\
\hline Sepsis & $210(20.0)$ & Patients with ca & it $(n=424[40.3$ & \\
\hline Trauma & $102(9.7)$ & Caloric target ${ }^{b}$ & Mean & Median \\
\hline Abdominal & $95(9.0)$ & kcal & $1703.7(446.5)$ & $1700.0(1400.0 ; 2000.0)$ \\
\hline Other & $86(8.2)$ & $\mathrm{kcal} / \mathrm{kg}$ & $26.7(7.0)$ & $25.0(22.2 ; 30.0)$ \\
\hline Not available & $8(0.8)$ & Caloric intake & Mean & Median \\
\hline IIme since icu admission, days & & kcal & $1014.9(463.7)$ & $1000.0(700.0 ; 1327.5)$ \\
\hline Mean (SD) & $27.6(62.2)$ & $\mathrm{kcal} / \mathrm{kg}$ & $15.8(7.2)$ & $15.8(10.7 ;$ 20.8) \\
\hline Median (range) & $10.0(0-465.0)$ & Caloric balance & Mean & Median \\
\hline uration of ICU stay on screening Day, n (\%) & & kcal & $-688.8(455.2)$ & $-577.0(-928.5 ;-327.5)$ \\
\hline $0-5$ days & $301(28.7)$ & $\mathrm{kcal} / \mathrm{kg}$ & $-10.8(7.0)$ & $-9.2(-14.9 ;-5.3)$ \\
\hline $\begin{array}{l}6-9 \text { days } \\
\geq 10 \text { days }\end{array}$ & $557(53.0)$ & $\begin{array}{l}\text { Abbreviations: } Q 1 \\
{ }^{\text {a }} \text { Data are presen } \\
{ }^{\mathrm{b}} \text { Clinician-derivec }\end{array}$ & $\begin{array}{l}\text { artile, } Q 3 \text { upper } q \\
\text { an }( \pm S D) \text { and me } \\
\text { ric target }\end{array}$ & $\begin{array}{l}\text { Q standard deviation } \\
\text { Q3) }\end{array}$ \\
\hline
\end{tabular}

Table 2 Patient characteristics (Continued)

Abbreviations: APACHE Acute Physiology and Chronic Health Evaluation, BMI body

Table 3 Caloric balance on day -1

are presented as mean (ISD) and median (Q1; Q3) 

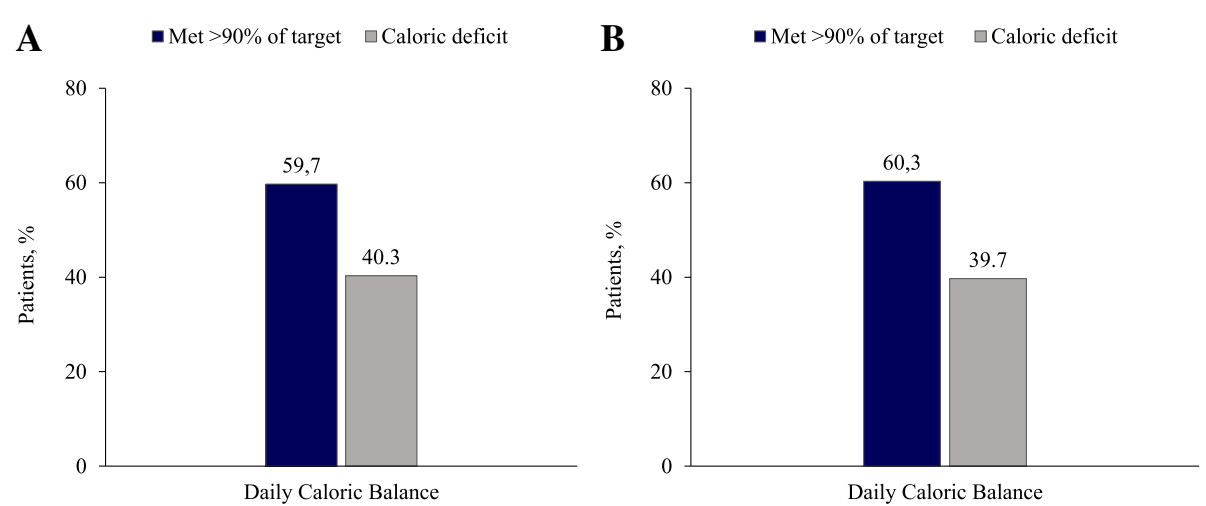

Fig. 2 Daily caloric balance based on a clinician-derived daily target and $\mathbf{b}$ standardised daily target*. *Defined as the difference between the daily caloric target and the sum of calories from enteral and/or parenteral nutrition and other sources of caloric intake

high nutrition-related risk and those with a score indicating a low risk.

\section{Secondary outcomes}

Analysis of cumulative caloric balance from day -5 to day -1 showed a mean cumulative caloric deficit of $768.9 \pm 2768.7 \mathrm{kcal}(-11.1 \pm 44.8 \mathrm{kcal} / \mathrm{kg})$. Caloric intake during the 5 -day observation period met $>90 \%$ of the clinician-derived cumulative target in $60.1 \%$ of patients and failed to meet the cumulative caloric goal in $39.9 \%$. Among the latter, caloric deficits accumulated rapidly, reaching a mean deficit of $-3225 \pm 2103 \mathrm{kcal}(-50.6 \pm$ $33.1 \mathrm{kcal} / \mathrm{kg}$ ) for the period from day -5 to day -1 (Fig. 4).

Protein intake on day -1 met $>90 \%$ of the daily target in $52.4 \%$ of patients and failed to reach the daily target in $47.6 \%$. The mean daily protein deficit on day -1 among patients for whom protein intake failed to meet the daily target was $-42.2 \pm 28.2 \mathrm{~g}(-0.7 \pm 0.4 \mathrm{~g} / \mathrm{kg})$. Evaluation of the cumulative protein balance during the 5 -day observation period showed that protein intake

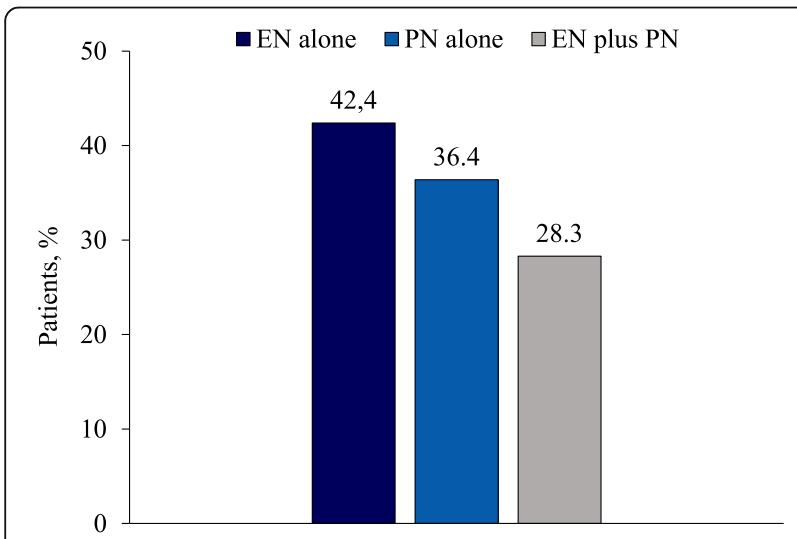

Fig. 3 Proportion of patients with caloric deficit on day -1 according to prescribed nutritional therapy. Abbreviations: EN enteral nutrition, PN parenteral nutrition met $>90 \%$ of the cumulative target in $53.9 \%$ of patients and failed to meet the cumulative target in $46.1 \%$. The overall mean cumulative protein deficit for the period from day -5 to day -1 was $-36.2 \pm 216.5 \mathrm{~g}(-0.5 \pm 3.4 \mathrm{~g} / \mathrm{kg})$. In patients who failed to meet the cumulative protein target, the mean cumulative protein deficit for the corresponding period was $-175.7 \pm 121.0 \mathrm{~g}(-2.7 \pm 1.8 \mathrm{~g} / \mathrm{kg})$ (Fig. 5). Assessment of daily protein balance according to the prescribed route of nutrition support showed that the proportion of patients with a protein deficit was higher among those who received EN alone (50.3\%) compared with either PN alone (37.4\%) or a combination of EN and PN (36.2\%).

Univariable (unadjusted) logistic regression analyses identified potential associations between attainment of daily caloric and protein targets on day -1 and various hospital and patient characteristics (Additional file 1: Appendix E). The results of the multivariable analyses

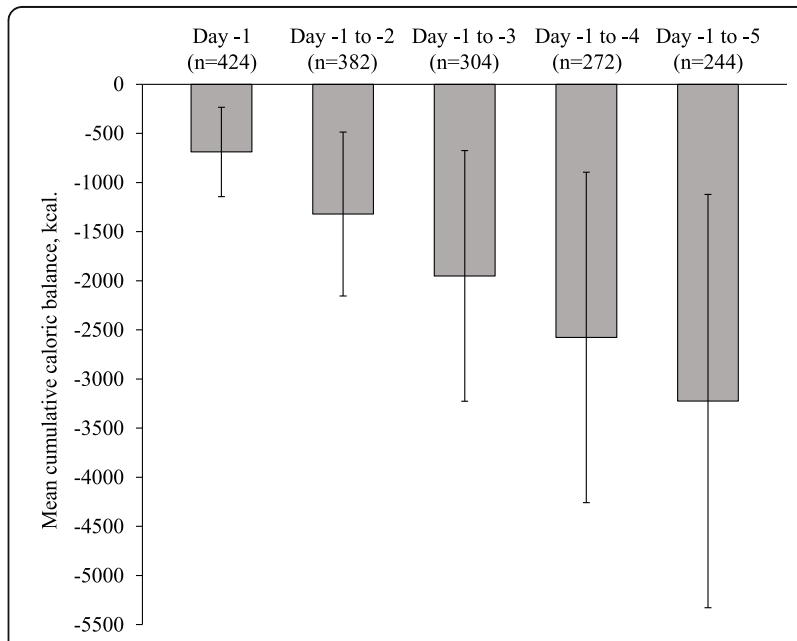

Fig. 4 Mean $( \pm S D)$ cumulative caloric balance in patients who did not meet the cumulative caloric target ${ }^{*}$. ${ }^{*}$ Defined as the sum of the mean daily caloric balance for all days from day -1 , calculated for each day from day -5 to day -1 


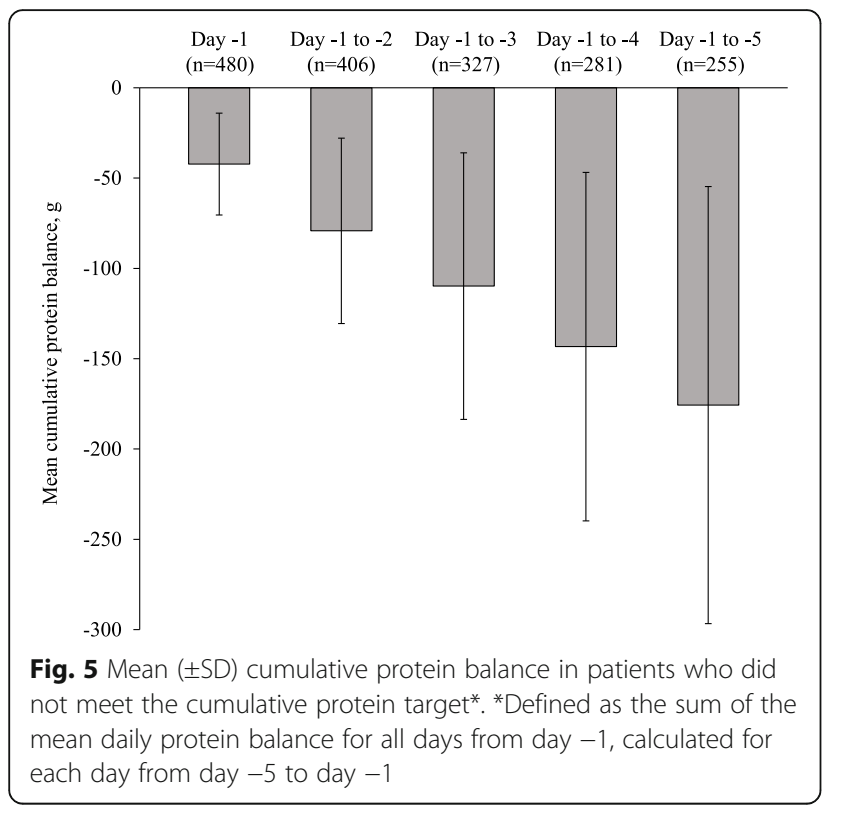

are presented in Table 4. After adjustment for model covariates, the following variables were associated with a statistically significant increase in the probability of meeting $>90 \%$ of the daily caloric target: female sex, BMI $<18.5 \mathrm{~kg} / \mathrm{m}^{2}$, suspected or moderate malnutrition according to the SGA, SOFA score $\geq 10$, and combined administration of EN and PN. Variables associated with an increased probability of meeting $>90 \%$ of the daily protein target included suspected or moderate malnutrition according to the SGA, administration of PN, and a duration of stay in the ICU before the Screening Day $>10$ days. The probability of meeting both the daily caloric target and the daily protein target was significantly increased among patients who received a combination of EN and PN as well as those with a $>10$-day duration of stay in the ICU before the Screening Day. Conversely, a BMI $\geq 30 \mathrm{~kg} / \mathrm{m}^{2}$ was associated with a significantly lower probability of meeting either the daily caloric target or the daily protein target.

Patient nutritional status and nutrition-related risk on day 0 are summarised in Table 5. Assessment of nutritional status using the SGA showed that $74.1 \%$ of patients were moderately to severely malnourished on the Screening Day. The ESPEN malnutrition score suggested the presence of malnutrition in $13.9 \%$ of patients. The NUTRIC score indicated a high need for nutritional therapy in $39.2 \%$.

More than $90 \%$ of patients received EN during the observation period; of these, $88.2 \%$ received EN alone and $11.8 \%$ received EN in combination with PN. Intestinal failure precluded initiation of EN in $17.7 \%$ of all patients and intolerance to EN was observed in $18.7 \%$. Diarrhoea, high gastric residual volume, and abdominal distention were the most commonly reported causes of intolerance to EN. Nutrition therapy was interrupted during the 5-day observation period in $25.7 \%$ of patients; the most common reasons for interruption were intolerance (43.1\%), diagnostic procedures (32.2\%), and surgery $(27.8 \%)$.

\section{Discussion}

The present study represents the first large multinational study evaluating nutrition practices and in adult critically ill ICU patients in Latin America. Analysis of data from 1053 patients in 116 hospitals in eight Latin American countries yielded several observations with important implications for the development of improved nutrition practices in patients with critical illness.

First, malnutrition is highly prevalent in critically ill adult patients in Latin America. More than $70 \%$ of all patients had moderate or severe malnutrition according to the SGA and nearly $40 \%$ had an increased risk of poor clinical outcomes according to the NUTRIC score. The ESPEN malnutrition score suggested the presence of malnutrition in only $13.9 \%$. To our knowledge, the current study is the first to apply the ESPEN diagnostic criteria to patients with critical illness. The observed difference in the proportion of patients classified as malnourished according to the SGA and the ESPEN criteria is likely attributable to the fact that the ESPEN definition does not account for the influence of disease severity or the increased metabolic demands in critically ill patients. The proportion of patients who were malnourished according to the SGA is consistent with a Brazilian study in which the reported prevalence of malnutrition among ICU patients with a duration of hospitalisation $>48$ hours was $70.3 \%$ [19]. In that study, malnourished patients had a significantly higher rate of readmission to the ICU (OR 2.27; 95\% CI 1.08-4.80) and a markedly increased risk of mortality compared with well-nourished patients (OR 8.12; CI 2.94-22.42). Coupled with these findings, the observed prevalence of malnutrition in the present study underscores the need for adequate nutritional screening and assessment, prompt intervention, and rigorous monitoring of nutritional status in this high-risk population.

Second, caloric intake failed to meet the established daily target in $40 \%$ of patients on day -1 , and a similar proportion of patients failed to achieve the caloric target during the 5-day observation period. Moreover, caloric deficits accumulated rapidly in these patients, resulting in a mean caloric deficit of $-3225 \mathrm{kcal}$ between day -5 and day -1 . This latter finding is particularly alarming, as caloric deficits in critically ill patients are associated with poor clinical outcomes, including infectious complications, prolonged duration of mechanical ventilation, and increased mortality [14, 27, 28]. Importantly, emerging evidence suggests that low but adequate caloric intake during the first few days following ICU admission may confer benefits to critically ill patients, particularly 
Table 4 Multivariable analysis of the association between reaching caloric and protein targets on day -1 and selected patient and hospital characteristics

\begin{tabular}{|c|c|c|c|}
\hline Outcome & Variable & OR $(95 \% \mathrm{Cl})$ & $p$ value $^{\mathrm{a}}$ \\
\hline \multirow{21}{*}{$\begin{array}{l}\text { Caloric target } \\
\text { reached }^{b}\end{array}$} & \multicolumn{3}{|l|}{ Sex } \\
\hline & Male & - & - \\
\hline & Female & $1.39(1.07,1.82)$ & 0.015 \\
\hline & \multicolumn{3}{|c|}{ Prescribed nutrition therapy } \\
\hline & EN alone & - & - \\
\hline & PN alone & $1.30(0.83,2.04)$ & 0.254 \\
\hline & EN plus PN & $1.64(1.04,2.57)$ & 0.032 \\
\hline & \multicolumn{3}{|l|}{ SGA score } \\
\hline & A (well nourished) & - & - \\
\hline & $\begin{array}{l}\text { B (moderately } \\
\text { malnourished) }\end{array}$ & $1.40(1.03,1.91)$ & 0.034 \\
\hline & $\begin{array}{l}\text { C (severely } \\
\text { malnourished) }\end{array}$ & $0.92(0.62,1.36)$ & 0.686 \\
\hline & \multicolumn{3}{|l|}{ SOFA score } \\
\hline & $<6$ & - & - \\
\hline & 6 to $<10$ & $1.25(0.93,1.67)$ & 0.138 \\
\hline & $\geq 10$ & $1.85(1.29,2.65)$ & $<0.001$ \\
\hline & \multicolumn{3}{|l|}{ BMI, $\mathrm{kg} / \mathrm{m}^{2}$} \\
\hline & $<18.5$ & $2.07(1.15,3.74)$ & 0.015 \\
\hline & 18.5 to $<20$ & $1.58(0.86,2.92)$ & 0.141 \\
\hline & 20 to $<22$ & $1.02(0.74,1.69)$ & 0.595 \\
\hline & 22 to $<30$ & - & - \\
\hline & $\geq 30$ & $0.61(0.43,0.87)$ & 0.006 \\
\hline \multirow{18}{*}{$\begin{array}{l}\text { Protein target } \\
\text { reached }^{b}\end{array}$} & \multicolumn{3}{|c|}{ Duration of ICU stay before day -1 } \\
\hline & $0-5$ days & - & - \\
\hline & $6-9$ days & $1.31(0.88,1.94)$ & 0.181 \\
\hline & $\geq 10$ days & $1.77(1.30,2.41)$ & $<0.001$ \\
\hline & \multicolumn{3}{|c|}{ Prescribed nutrition therapy } \\
\hline & EN alone & - & - \\
\hline & PN alone & $1.79(1.14,2.81)$ & 0.011 \\
\hline & EN plus PN & $1.43(0.92,2.23)$ & 0.110 \\
\hline & \multicolumn{3}{|l|}{ SGA score } \\
\hline & A (well nourished) & - & - \\
\hline & $\begin{array}{l}\text { B (moderately } \\
\text { malnourished) }\end{array}$ & $1.54(1.12,2.12)$ & 0.008 \\
\hline & $\begin{array}{l}\text { C (severely } \\
\text { malnourished) }\end{array}$ & $0.88(0.59,1.32)$ & 0.547 \\
\hline & \multicolumn{3}{|l|}{$\mathrm{BMI}, \mathrm{kg} / \mathrm{m}^{2}$} \\
\hline & $<18.5$ & $1.59(0.91,2.78)$ & 0.102 \\
\hline & 18.5 to $<20$ & $1.76(0.97,3.09)$ & 0.064 \\
\hline & 20 to $<22$ & $1.21(0.80,1.82)$ & 0.373 \\
\hline & 22 to $<30$ & - & - \\
\hline & $\geq 30$ & $0.45(0.31,0.64)$ & $<0.001$ \\
\hline
\end{tabular}

Duration of ICU stay before day -1
Table 4 Multivariable analysis of the association between reaching caloric and protein targets on day -1 and selected patient and hospital characteristics (Continued)

\begin{tabular}{|c|c|c|c|}
\hline \multirow{13}{*}{$\begin{array}{l}\text { Both caloric and } \\
\text { protein target } \\
\text { reached }^{\mathrm{b}}\end{array}$} & $0-5$ days & - & - \\
\hline & 6-9 days & $1.38(0.94,2.03)$ & 0.103 \\
\hline & $\geq 10$ days & $1.69(1.25,2.29)$ & $<0.001$ \\
\hline & \multicolumn{3}{|c|}{ Prescribed nutrition therapy } \\
\hline & EN alone & - & - \\
\hline & PN alone & $1.39(0.91,2.13)$ & 0.132 \\
\hline & EN plus PN & $1.56(1.02,2.39)$ & 0.038 \\
\hline & \multicolumn{3}{|l|}{$\mathrm{BMI}, \mathrm{kg} / \mathrm{m}^{2}$} \\
\hline & $<18.5$ & $1.58(0.94,2.67)$ & 0.084 \\
\hline & 18.5 to $<20$ & $1.56(0.89,2.73)$ & 0.120 \\
\hline & 20 to $<22$ & $1.20(0.81,1.77)$ & 0.373 \\
\hline & 22 to $<30$ & - & - \\
\hline & $\geq 30$ & $0.49(0.34,0.70)$ & $<0.001$ \\
\hline
\end{tabular}

Abbreviations: $B M I$ body mass index, $\mathrm{Cl}$ confidence interval, $E N$ enteral nutrition, $O R$ odds ratio, $P N$ parenteral nutrition, SGA Subjective Global Assessment, SOFA Sequential Organ Failure Assessment

aald test

${ }^{b}>90 \%$ of daily target

Table 5 Patient nutritional status and nutrition-related risk

\begin{tabular}{|c|c|c|}
\hline Patients, n (\%) & & Total $(N=1053)$ \\
\hline \multirow[t]{9}{*}{ Nutritional status } & \multicolumn{2}{|c|}{ Subjective Global Assessment (SGA) } \\
\hline & Well nourished $(A)$ & $261(25.9)$ \\
\hline & Moderately malnourished (B) & $512(50.9)$ \\
\hline & Severely malnourished (C) & $233(23.2)$ \\
\hline & Missing & 47 \\
\hline & \multicolumn{2}{|l|}{ ESPEN malnutrition score } \\
\hline & Well nourished & $816(86.1)$ \\
\hline & Malnourished ${ }^{a}$ & $132(13.9)$ \\
\hline & Missing & 105 \\
\hline \multirow[t]{4}{*}{ Nutrition-related risk } & \multicolumn{2}{|l|}{ NUTRIC score } \\
\hline & Low risk ${ }^{b}$ & $561(60.8)$ \\
\hline & High risk ${ }^{c}$ & $362(39.2)$ \\
\hline & Missing & 130 \\
\hline
\end{tabular}

Abbreviations: BMI body mass index, ESPEN European Society for Clinical Nutrition and Metabolism; FFMI fat-free mass index, IL-6 interleukin-6, NUTRIC Nutrition Risk in the Critically III

${ }^{a}$ Defined as (a) BMI $<18.5 \mathrm{~kg} / \mathrm{m}^{2}$ or (b) combination of unintentional weight loss ( $>10 \%$ over an undefined time period or $>5 \%$ during previous 3 months) and either low BMI $\left(<20 \mathrm{~kg} / \mathrm{m}^{2}\right.$ [age $<70$ years] or $<22 \mathrm{~kg} / \mathrm{m}^{2}$ [age $\geq 70$ years]) or low FFMI $\left(<15 \mathrm{~kg} / \mathrm{m}^{2}\right.$ [women] or $<17 \mathrm{~kg} / \mathrm{m}^{2}$ [men])

${ }^{\mathrm{b}} \mathrm{S}$ core of $0-5$ for patients with available IL-6 concentration or $0-4$ for patients with no available IL- 6 concentration

'Score of 6-10 for patients with available IL-6 concentration or 5-9 for patients with no available IL- 6 concentration 
when coupled with increased protein intake [11, 12]. Of note, sensitivity analysis of caloric balance using a caloric target of $20 \mathrm{kcal} / \mathrm{kg} / \mathrm{d}$ for the first 6 days in the ICU and $25 \mathrm{kcal} / \mathrm{kg} / \mathrm{d}$ thereafter showed no meaningful difference in the observed proportion of patients with a caloric deficit.

Third, while more than $90 \%$ of patients received EN, PN use was low. Fewer than one in ten patients received $\mathrm{PN}$ alone and slightly more than $10 \%$ received a combination of EN and PN. This finding is consistent with the recent Nutrition Day ICU survey in which 10\% and 12\% of patients received $\mathrm{PN}$ and combined $\mathrm{EN}$ and $\mathrm{PN}$, respectively [29]. In contrast to the limited use of PN observed during the present study, the clinical characteristics of the population suggested a need for broader use. More than $75 \%$ of patients required mechanical ventilation, $74 \%$ had suspected/moderate or severe malnutrition according to the SGA, and more than one-third of all patients had either a contraindication or intolerance to EN. Notably, patients who received EN alone had a larger mean daily caloric deficit on day -1 compared with those who received either $\mathrm{PN}$ or a combination of $\mathrm{EN}$ and $\mathrm{PN}$, and a higher proportion of patients who received EN alone failed to meet at least $90 \%$ of the daily caloric target compared with those who received $\mathrm{PN}$ or combined EN and PN. A previous randomised controlled trial of 305 critically ill patients with persistent energy deficits following 3 days of EN showed that supplemental administration of PN improved the cumulative energy balance compared with continued administration of EN alone [30]. The effects of supplemental PN and caloric intake on clinical outcome parameters are discussed controversially [30-36]. However, current recommendations indicate that persistent energy and protein deficits for 2 days (ESPEN guidelines) or 7-10 days (A.S.P.E.N. guidelines) in patients receiving $\mathrm{EN}$ alone should prompt the clinician to consider the use of supplemental PN to improve energy and protein delivery and potentially reduce the risk of adverse clinical outcomes $[11,12]$. The results of the present study show that supplemental PN reduces energy and protein deficits but suggest that the supplemental use of PN is not optimally employed as a therapeutic strategy in patients who fail to receive adequate nutrition intake from $\mathrm{EN}$ alone.

Finally, logistic regression analysis identified a statistically significant association between achieving $>90 \%$ of the targeted energy and protein delivery on day -1 and the type of prescribed nutritional therapy. Combined administration of EN and PN was associated with a $64 \%$ increase in the likelihood of meeting $>90 \%$ of the daily caloric target on day -1 and a $56 \%$ increase in the probability of meeting $>90 \%$ of both the daily caloric target and the daily protein target compared with EN alone. Given the relatively low use of PN in the present study and the observed improvements in cumulative energy balance among ICU patients receiving supplemental PN in a previous randomised trial [30], the association between supplemental PN and caloric and protein target attainment in the present study suggests an opportunity to improve energy and protein delivery in critically ill patients in Latin America through the incorporation of supplemental PN into the routine nutritional management plan. Common practice in Latin America is to use EN before adding or switching to PN whenever EN is not contraindicated. In view of this general approach of dynamically adapting EN and PN (including SPN) to meet individual nutritional requirements, the current results clearly suggest an opportunity for further improvements in optimising nutrition delivery to reach defined nutritional targets.

The strengths of our study include the large sample size and the high rate of data ascertainment for the parameters of interest. Additionally, in contrast to studies in which patients share a common starting point at the time of ICU admission, the design of the present study allowed for a representative mix of patients with different durations of ICU stay before the time of the assessment. Moreover, the study population included a high proportion of patients with a long duration of ICU stay, thereby facilitating assessment of the relationship between longer duration of stay and prescribed nutrition therapy.

The findings of our study are subject to certain limitations, including those inherent to cross-sectional study design and retrospective analysis. Additionally, due to lower than expected recruitment on the Screening Day, the sample size was smaller than the originally planned sample size of 2000 patients. Based on an estimated 50\% prevalence of malnutrition, the original calculation showed that a sample size of 2000 patients would provide a confidence interval with a precision of $\pm 2.2 \%$. Recalculation based on the observed $74 \%$ prevalence of malnutrition and the actual sample size of 1053 patients yielded a confidence interval with a precision of $\pm 2.7 \%$. The marginal difference in the precision of the confidence intervals between sample sizes of 1053 and 2000 patients $(0.5 \%)$ suggests that the smaller sample size had a negligible effect on the precision of the estimates. A substantial majority of hospitals in the study were academic institutions (83.7\%) and $39.7 \%$ of the ICUs had a specialised nutritional team; accordingly, the extent to which the findings are generalisable to local/community hospitals is uncertain. Moreover, patients were required to be receiving nutrition therapy on both the Screening Day and the previous day; therefore, the degree to which nutrition therapy is optimally employed across the full population of critically ill patients in the ICU setting cannot be reliably ascertained. Finally, both the prevalence of underfeeding and the magnitude of caloric deficits observed in the present study were lower than those 
reported in a recent prospective study in nutritionally at-risk critically ill patients [37]. This might be explained in part by the cross-sectional design of the present study, which resulted in a longer pre-screening duration of ICU stay. The median duration of stay in the ICU on the Screening Day was 10 days, reflecting a mixed population of acute and chronically ill patients. The previous study [37] evaluated patients beginning 96 hours after admission to the ICU and therefore included a larger proportion of patients in the acute phase of illness. Other potential explanations for the observed differences include a lower proportion of patients with gastrointestinal intolerance, a lower proportion of patients requiring invasive respiratory support, a higher proportion of hospitals with nutrition therapy teams, and a higher proportion of patients who received PN compared with the previous study. However, despite these differences, the results of the two studies are directionally consistent and provide compelling corroborative evidence of the need for improved nutrition practices to optimise energy provision in critically ill patients.

\section{Conclusions}

Comprehensive assessment of the nutritional status of critically ill adults receiving EN and/or $\mathrm{PN}$ in Latin American hospitals identified caloric deficits in more than $40 \%$ of patients on EN, with lower deficits observed in patients receiving a combination of EN and PN. Coupled with the low rates of PN use observed in the study, these data suggest an opportunity for more effective utilisation of supplemental PN in critically ill adults who fail to receive adequate nutrition intake from EN alone.

\section{Additional files}

Additional file 1: Appendix A Subjective Global Assessment (SGA) Questionnaire. Appendix B Nutrition Risk in the Critically III (NUTRIC) Score. Appendix C ESPEN Diagnostic Criteria for Adult Malnutrition. Appendix D Hospital characteristics. Appendix E Univariable analyses-association between daily caloric and protein balance and selected hospital and patient characteristics. Appendix F Screening Day Latin America investigators and study sites. (PDF $371 \mathrm{~kb}$ )

Additional file 2: Ethics committee approvals. (PDF $225 \mathrm{~kb}$ )

\section{Abbreviations}

APACHE II: Acute Physiology and Chronic Health Evaluation II; A.S.P.E.N.: American Society for Parenteral and Enteral Nutrition; BMI: Body mass index; EN: Enteral nutrition; ESPEN: European Society for Clinical Nutrition and Metabolism; ICU: Intensive care unit; NUTRIC: Nutrition Risk in the Critically III; PN: Parenteral nutrition; SD: Standard deviation; SGA: Subjective Global Assessment; SOFA: Sequential Organ Failure Assessment

\section{Acknowledgements}

We are indebted to the patients and family members who participated in the study. We also wish to thank the participating institutions as well as the members of United for Clinical Nutrition. Finally, we thank Fresenius Kabi GmbH for sponsorship of the study, IMS Health for the operational support, and Kenneth Glasscock (KFG Scientific Communications, United States) for medical writing and editorial assistance.

\section{Funding}

This study was funded by Fresenius Kabi Deutschland $\mathrm{GmbH}$.

\section{Availability of data and materials}

The datasets used and/or analysed during the current study are available from the corresponding author on reasonable request.

\section{Authors' contributions}

All authors co-designed the study, actively discussed the study results, and finalised the manuscript. All authors read and approved the final manuscript.

\section{Authors' information}

Not applicable.

\section{Ethics approval and consent to participate}

The study protocol was approved by the local ethics committee or institutional review board at participating institutions in accordance with local regulations for non-interventional studies (Additional file 2). Where required by local regulations or ethics committee policy, written informed consent was obtained from each patient or family member before enrollment.

\section{Consent for publication}

Not applicable.

\section{Competing interests}

KPV, CMM, AAMA, VFT, GCCN, RERP, MIP, MITDC, and DLW have served on an advisory board for Fresenius Kabi. GCCN has served as a consultant for Global Mix Pharma. MITDC has served as an advisor for Abbot and Baxter and received honoraria for lectures from Abbott, Baxter, Fresenius Kabi, Nestlé, and Sanofi, and research support from Invictus. MIP has received honoraria for lectures from Fresenius Kabi. DLW has served as an advisor for Danone and received honoraria for lectures from Ache, B. Braun, Danone, and Fresenius Kabi.

\section{Publisher's Note}

Springer Nature remains neutral with regard to jurisdictional claims in published maps and institutional affiliations.

\section{Author details}

${ }^{1}$ Intensive Care and Nutrition Unit, Hospital Clínico de la Universidad de Chile, Santiago de Chile, Chile. ²Universidad Militar Nueva Granada, Bogotá, Colombia. ${ }^{3}$ Complejo Hospitalario de la Caja del Seguro Social de Panamá, Panama City, Panama. ${ }^{4}$ Hospital General de México, Mexico City, Mexico. ${ }^{5}$ Hospital Guillermo Kaelin de la Fuente, Villa María del Triunfo, Peru. ${ }^{6}$ Hospital Metropolitano, Quito, Ecuador. ${ }^{7}$ Adult Intensive Care Unit, Department of Medicine, Italian Hospital of Buenos Aires, Buenos Aires, Argentina. ${ }^{8}$ Universidade Federal de Minas Gerais Medical School, Av. Carandaí 246 Apt. 902, Belo Horizonte 30130-060, Brazil. ${ }^{9}$ Department of Gastroenterology, University of São Paulo Medical School, São Paulo, Brazil.

Received: 28 March 2017 Accepted: 1 August 2017

Published online: 25 August 2017

\section{References}

1. White JV, Guenter P, Jensen G, et al. Consensus Statement: Academy of Nutrition and Dietetics and American Society for Parenteral and Enteral Nutrition: characteristics recommended for the identification and documentation of adult malnutrition (undernutrition). JPEN J Parenter Enteral Nutr. 2012;36:275-83.

2. Correia MI, Waitzberg DL. The impact of malnutrition on morbidity, mortality, length of hospital stay, and costs evaluated through a multivariate model analysis. Clin Nutr. 2003;22:235-9.

3. Stratton RJ, King CL, Stroud MA, Jackson AA, Elia M. 'Malnutrition Universal Screening Tool' predicts mortality and length of hospital stay in acutely ill elderly. Br J Nutr. 2006;95:325-30.

4. Norman K, Pichard C, Lochs H, Pirlich M. Prognostic impact of disease-related malnutrition. Clin Nutr. 2008;27:5-15.

5. Sorensen J, Kondrup J, Prokopowicz J, et al. EuroOOPS: an international, multicentre study to implement nutritional risk screening and evaluate clinical outcome. Clin Nutr. 2008;27:340-9. 
6. Lim SL, Ong KC, Chan YH, Loke WC, Ferguson M, Daniels L. Malnutrition and its impact on cost of hospitalization, length of stay, readmission and 3-year mortality. Clin Nutr. 2012;31:345-50.

7. Alvarez-Hernandez J, Planas Vila M, León-Sanz M, et al. Prevalence and costs of malnutrition in hospitalized patients; the PREDyCES Study. Nutr Hosp. 2012;27:1049-59.

8. Brito PA, de Vasconcelos GS, Correia MI. Prevalence of pressure ulcers in hospitals in Brazil and association with nutritional status-a multicenter, cross-sectional study. Nutrition. 2013;29:646-9.

9. Waitzberg DL, Caiaffa WT, Correia MI. Hospital malnutrition: The Brazilian national survey (IBRANUTRI): A study of 4000 patients. Nutrition. 2001;17:573-80.

10. Leandro-Merhi VA, de Aquino JL, Sales Chagas JF. Nutrition status and risk factors associated with length of hospital stay for surgical patients. JPEN J Parenter Enteral Nutr. 2011:35:241-8.

11. McClave SA, Taylor BE, Martindale RG, et al. Guidelines for the provision and assessment of nutrition support therapy in the adult critically ill patient: Society of Critical Care Medicine (SCCM) and American Society for Parenteral and Enteral Nutrition (A.S.P.E.N.). JPEN J Parenter Enteral Nutr. 2016;40:159-211.

12. Singer $P$, Berger $M M$, Van den Berghe $G$, et al. ESPEN guidelines on parenteral nutrition: Intensive care. Clin Nutr. 2009;28:387-400.

13. Lewis SJ, Egger M, Sylvester PA, et al. Early enteral feeding versus "nil by mouth" after gastrointestinal surgery: systematic review and meta-analysis of controlled studies. BMJ. 2001;323:773-6.

14. Villet $\mathrm{S}$, Chiolero RL, Bollman MD, et al. Negative impact of hypocaloric feeding and energy balance on clinical outcome in ICU patients. Clin Nutr. 2005;24:502-9.

15. Sandström R, Drott C, Hyltander A, et al. The effect of postoperative intravenous feeding (TPN) on outcome following major surgery evaluated in a randomized study. Ann Surg. 1993;217:185-95.

16. McClave SA, Chang WK, Dhaliwal R, Heyland DK. Nutrition support in acute pancreatitis: a systemic review of the literature. JPEN J Parenter Enteral Nutr. 2006;30:143-56.

17. Worthington $\mathrm{P}$, Balint J, Bechtold $\mathrm{M}$, et al. When is parenteral nutrition appropriate? J Parenter Enteral Nutr. 2017:41:324-77.

18. Blaser AR, Starkopf J, Alhazzani W, et al. Early enteral nutrition in critically ill patients: ESICM clinical practice guidelines. Intensive Care Med. 2017;43:380-98.

19. Fontes D, de Vasconcelos GS, Correia MI. Subjective global assessment: A reliable nutritional assessment tool to predict outcomes in critically ill patients. Clin Nutr. 2014;33:291-5.

20. Hamwi GJ. Therapy: changing dietary concepts. In: Danowski TS, editor. Diabetes mellitus: diagnosis and treatment (vol. 1). New York: American Diabetes Association; 1964. p. 73-8.

21. Detsky AS, McLaughlin JR, Baker JP, et al. What is subjective global assessment of nutritional status? J Parenter Enteral Nutr. 1987;11:8-13.

22. Sheean PM, Peterson SJ, Gurka DP, Braunschweig CA. Nutrition assessment: the reproducibility of subjective global assessment in patients requiring mechanical ventilation. Eur J Clin Nutr. 2010;64:1358-64.

23. Heyland DK, Dhaliwal $R$, Jiang $X$, Day AG. Identifying critically ill patients who benefit the most from nutrition therapy: the development and initial validation of a novel risk assessment tool. Crit Care. 2011;15:R268.

24. Rahman A, Hasan RM, Agarwala R. Identifying critically-ill patients who benefit most from nutritional therapy: further validation of the modified NUTRIC score. Clin Nutr. 2016;35(1):158-62. doi:10.1016/j.clnu.2015.01.015.

25. Cederholm T, Bosaeus I, Barazzoni R, et al. Diagnostic criteria for malnutrition-an ESPEN Consensus Statement. Clin Nutr. 2015;34:335-40.

26. Correia MI, Campos AC. Prevalence of hospital malnutrition in Latin America: the multicenter ELAN study. Nutrition. 2003;19:823-5.

27. Dvir D, Cohen J, Singer P. Computerized energy balance and complications in critically ill patients: an observational study. Clin Nutr. 2005;25:37-44.

28. Rubinson L, Diette GB, Song X, Brower RG, Krishnan JA. Low caloric intake is associated with nosocomial bloodstream infections in patients in the medical intensive care unit. Crit Care Med. 2004;32:350-7.

29. Bendavid I, Singer $P$, Thellia $M$, et al. NutritionDay ICU: a 7 year worldwide prevalence study of nutrition practice in intensive care. Clin Nutr. 2017;36:1122-9.

30. Heidegger CP, Berger MM, Graf S, et al. Optimisation of energy provision with supplemental parenteral nutrition in critically ill patients: a randomised controlled clinical trial. Lancet. 2013;381:385-93.
31. Casaer MP, Mesotten D, Hermans G, et al. Early versus late parenteral nutrition in critically ill adults. N Engl J Med. 2011;365:506-17.

32. Singer $\mathrm{P}$, Anbar $\mathrm{R}$, Cohen J, et al. The tight calorie control study (TICACOS): a prospective, randomized, controlled pilot study of nutritional support in critically ill patients. Intensive Care Med. 2011;37:601-9.

33. Charles EJ, Petroze RT, Metzger R, et al. Hypocaloric compared with eucaloric nutritional support and its effect on infection rates in a surgical intensive care unit: a randomized controlled trial. Am J Clin Nutr. 2014;100:1337-43.

34. Petros S, Horbach M, Seidel F, Weidhase L. Hypocaloric vs normocaloric nutrition in critically ill patients: a prospective randomized pilot trial. JPEN J Parenter Enter Nutr. 2016;40:242-9.

35. Arabi YM, Aldawood AS, Haddad SH, et al. PermiT Trial Group. Permissive underfeeding or standard enteral feeding in critically ill adults. N Engl J Med. 2015;372:2398-408.

36. Rugeles S, Villarraga-Angulo LG, Ariza-Gutiérrez A, et al. High-protein hypocaloric vs normocaloric enteral nutrition in critically ill patients: a randomized clinical trial. J Crit Care. 2016;35:110-4.

37. Heyland DK, Dhaliwal R, Wang M, Day AG. The prevalence of iatrogenic underfeeding in the nutritionally 'at-risk' critically ill patient: results of an international, multicenter, prospective study. Clin Nutr. 2015;34:659-66.

\section{Submit your next manuscript to BioMed Central and we will help you at every step:}

- We accept pre-submission inquiries

- Our selector tool helps you to find the most relevant journal

- We provide round the clock customer support

- Convenient online submission

- Thorough peer review

- Inclusion in PubMed and all major indexing services

- Maximum visibility for your research

Submit your manuscript at www.biomedcentral.com/submit 